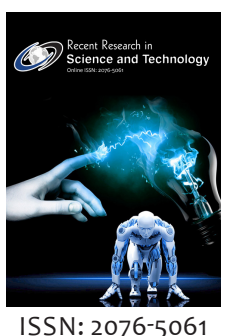

*Corresponding Author: Kinley Bidha

Email: kinley.bidha@auw.edu.bd

\section{Prevalence of hypertension and associated risk factors among Bhutanese Monks in Thimphu, Bhutan: A cross-sectional study}

\author{
Kinley Bidha*, Nazmul Alam \\ Department of Public Health, Asian University for Women, Chittagong, 20/A M.M. Ali Road, Chittagong 4000, \\ Bangladesh
}

\begin{abstract}
Hypertension is a major health problem and it accounts for more than 9.4 million people to die every year globally due to its high complications. It is a major risk factor for cardiovascular diseases and high research importance has been given due to its high prevalence. The objective of the present study was to determine the prevalence of hypertension and to assess its risk factors among monks populations in Thimphu. A cross-sectional study with purposive sampling method was conducted among the five different monasteries in Thimphu. A self administered questionnaire was structured for 307 monks from age 18 and above. The prevalence rate of hypertension in the present study was $32.6 \%$ among Bhutanese monks. Hypertension is significantly higher in elder age groups which conclude that hypertension increase with the increase of age and have a strong association. Alcohol use, betel consumption, and physical inactivity were found to be significant risk factors for developing hypertension. With the $32.6 \%$ prevalence rate, only $26 \%$ of them are receiving medications. There is an impending need for effective intervention strategies.
\end{abstract}

KEYWORDS: Hypertension, blood pressure, risk factor, prevalence, thimphu

\section{INTRODUCTION}

Hypertension is a major public health issue all around the globe due to its high prevalence and impact on other chronic diseases [1] According to Hien et al (2018), it accounts for 9.4 million deaths worldwide every year due to its high complications. Hypertension has been identified as a major cause of morbidity and mortality for cardiovascular diseases worldwide [2]. Hypertension is associated with several risk factors and approximately one-third of the adult population in the South East Asia Region has hypertension according to its country's diverse population size, land area, sociopolitical environment, economy, and health care system according to WHO report (2014) [3]. The rate of noncommunicable diseases has increased drastically over the past few years and has become a challenging issue which is hitting the LMCs and Bhutan is one of them.

The burden it has caused to the people and the country has contributed to the slow progressing of Bhutan's economy which ultimately hampers the whole health system. Bhutan currently has 700,000 populations residing in four different geographical areas such as western, eastern, southern and indigenous parts. A survey conducted in Thimphu by Ministry of Health in 2009 for NCDs among adults Bhutanese has found that the magnitude of NCDs is greater in the capital city than in other rural parts of Bhutan. About 93\% of the respondents were exposed to at least one of the common NCDs risk factors, including unhealthy diet, physical inactivity, and consumption of alcohol and/or tobacco [4].

According to the Annual Health Bulletin (2017) at present, the proportion of the population with hypertension is estimated at 35.7 in the country and the cases have increased to 30,260 in 2016 from 27,023 cases in 2012. Hypertension cases among Bhutanese population have increased dramatically. Its prevalence has significantly increased over the past decades due to urbanization, population aging, dietary habits and lifestyle in Bhutan as covered in the research conducted in Bhutan [5]. There are only a few research studies being conducted on hypertension and CVDs in Bhutan and thus, obtaining information and findings was difficult. There is not enough data on the prevalence of hypertension among different segments of the population. The surveys and studies carried out in Bhutan have their participation from various groups

Copyright: (-) The authors. This article is open access and licensed under the terms of the Creative Commons Attribution License (http://creativecommons.org/licenses/by/4.0/) which permits unrestricted, use, distribution and reproduction in any medium, or format for any purpose, even commercially provided the work is properly cited. Attribution - You must give appropriate credit, provide a link to the license, and indicate if changes were made. 
of the population but they have failed to include the monks' population who are also considered susceptible to hypertension. They are a small religious group from the monastic body in Bhutan. Due to their sedentary living style, they are also at very high risk of developing such complications. Monks spend most of their time in the monasteries praying and not involved in vigorous physical activities. They are also heavily engaged in religious activities where they are hosted nicely by the sponsors and home-owners where the celebration is held. During this time, monks are served with fatty foods such as fried butter, fatty meats, cheese, and even alcohol as part of the celebration. Thus, the consumption pattern and their inactive life do not match and this has been one of the major concerns in the country. Till date, only one research has been carried out among the monks' group, therefore, the main goal of this study is to find out the prevalence and its associated risk factors among the monks residing in the urban and rural areas in Thimphu district. The findings of this study are expected to contribute to the intervention strategies for the prevention of hypertension and its complication in Bhutan and to fill the research gap.

\section{METHODOLOGY}

\section{Study Design, Study Area and Sample Size}

A cross-sectional research study was carried out among monks aged 18 years and above living in Thimphu district in Bhutan. The study subjects were included from five different monasteries from both rural and urban areas. The sample size for the present study was calculated with an estimated prevalence of hypertension as $21 \%$ and permissible error as $5 \%$ with a $95 \%$ confidence interval. The sample size was calculated as $n=255$ and was further increased with a non-response rate of $20 \%$. The final sample size was 307 .

\section{Sampling Methods}

Purposive sampling method and a self-administered questionnaire was used to collect the data. The survey was translated into the national language of Bhutan, Dzongkha. There were three categories; Part 1: Socio-demographic characteristics- age, education level, monastic education, duration as monks and ethnicity. Part 2: Knowledge level of Hypertension- medications, risk factors, and other diseases. Part 3: modifiable behavioral risk factors-food habits, alcohol consumption, low physical activity, tobacco use, overweight, and high blood pressure. A face-to-face interview was conducted maintaining privacy.

Blood pressure was measured three times using manual Sphygmomanometer device and the average of three readings was considered.

Hypertensive subjects were defined as those with systolic blood pressure (SBP) equal to or more than $140 \mathrm{mmHg}$ and/or diastolic blood pressure (DBP) equal to or more than $90 \mathrm{mmHg}$. Three readings were taken with five hours of interval. Those having their SBP $>140 \mathrm{mmHg}$ or $\mathrm{DBP}>90$, they were told to refer to the national hospital as soon as possible and explained the complications.
Anthropometric measurements body weight was obtained with a weighing scale with a capacity of $130 \mathrm{~kg}$, calibrated, placed on a level surface and height was measured with an inelastic measuring tape with a length of $200 \mathrm{~cm}$. Body mass index was calculated directly using the WHO BMI standard chart.

\section{Ethical Consideration}

Ethical approval was obtained from the Ethical Research Committee of Asian University for Women. Permission was obtained from the Monastic Body of Bhutan (Draktshang Lengtsho). Written informed consent was obtained from the subjects for participation in the present study.

\section{Data Management and Analysis}

Information obtained from the survey was entered in MS Excel with a secured password. SPSS 20.0 program was used to carry out descriptive analysis, chi-square test, bivariate, and multivariate analysis. Multivariate regression analysis was performed to assess the risk factors of hypertention. Age, education, duration as monk, use of alcohol, use of betal leaf, body mass index were used a predicor varibles. Odds ratio and corresponding $95 \%$ confidence intervals were calculated.

\section{RESULTS}

\section{Socio Demographic Characteristics}

The mean age $( \pm \mathrm{SD})$ of the study subjects was $30.77( \pm 13.48)$ years. One-third of the subjects are either overweight or

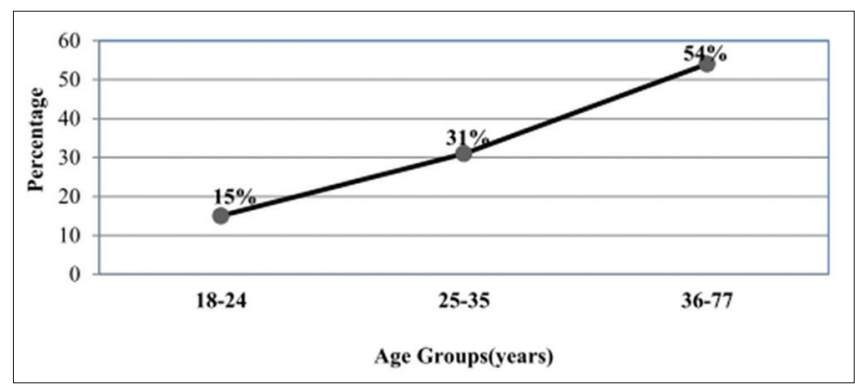

Figure 1: Prevalence of hypertension by Age

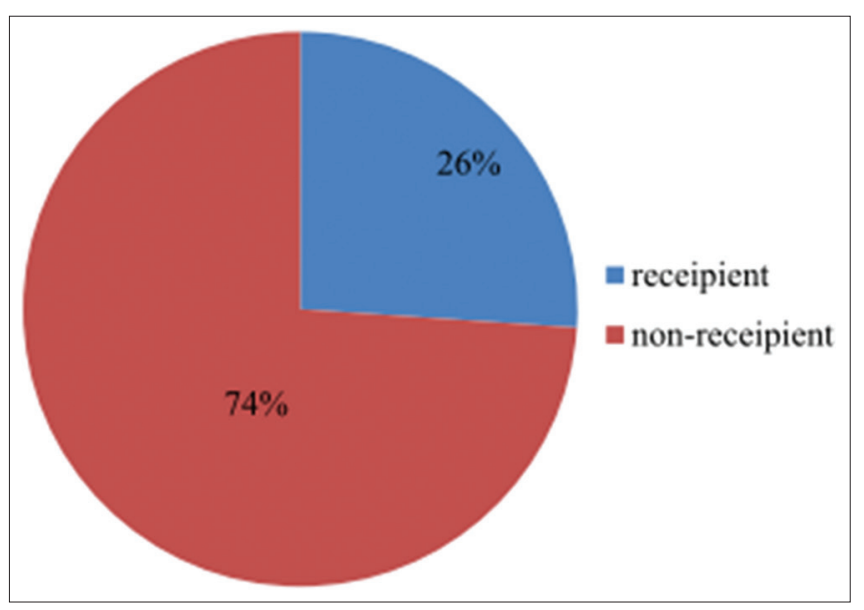

Figure 2: Percentage of subjects receiving hypertension medications 
Table 1: Multivariate analysis for risk factors of hypertension with odds ratio at $95 \%$ Confidence Interval 0.05

\begin{tabular}{|c|c|c|c|c|c|}
\hline \multirow[b]{2}{*}{ Variable } & \multirow[b]{2}{*}{ Subgroups } & \multicolumn{4}{|c|}{ Odds Ratio } \\
\hline & & Crude ratio $(95 \%$ C.I $)$ & $\mathrm{p}$ value & Adjusted ratio $(95 \%$ C.I) & $\mathrm{p}$ value \\
\hline \multirow[t]{3}{*}{ Age Group (yrs) } & $18-24$ & reference & & & \\
\hline & $25-35$ & $2.9(1.46-5.76)$ & 0.002 & $2.73(1.33-5.61)$ & 0.006 \\
\hline & $36-77$ & $10.7(5.36-21.35)$ & $<0.001$ & $15.81(6.10-41.02)$ & $<0.001$ \\
\hline \multirow[t]{4}{*}{ Education level } & Illiterate & reference & & & \\
\hline & Primary & $0.66(0.38-1.15)$ & 0.1 & $2.16(0.92-5.04)$ & 0.08 \\
\hline & Secondary & $0.45(0.21-1.04)$ & 0.06 & $1.13(0.36-3.53)$ & 0.83 \\
\hline & Tertiary & $0.9(0.31-2.71)$ & 0.85 & $2.89(0.67-12.51)$ & 0.16 \\
\hline \multirow{3}{*}{$\begin{array}{l}\text { Duration } \\
\text { as Monks }\end{array}$} & $1-20$ years & reference & & & \\
\hline & 21.40 years & $3.14(1.61-6.17)$ & 0.001 & $0.73(0.25-2.15)$ & 0.57 \\
\hline & $>41$ years & $3.62(1.46-8.97)$ & 0.006 & $0.57(0.14-2.35)$ & 0.44 \\
\hline \multirow[t]{2}{*}{ Alcohol use } & No & reference & & & \\
\hline & Yes & $0.43(0.25-0.75)$ & 0.003 & $0.47(0.24-0.94)$ & 0.03 \\
\hline \multirow[t]{2}{*}{ Betel use } & No & reference & & & \\
\hline & Yes & $0.96(0.59-1.56)$ & 0.81 & $2.03(1.08-3.82)$ & 0.03 \\
\hline \multirow[t]{3}{*}{ Body Mass Index } & Underweight & reference & & & \\
\hline & Overweight & $3.47(1.10-11.03)$ & 0.03 & $1.73(0.45-6.45)$ & 0.42 \\
\hline & Obese & $5.81(1.44-23.36)$ & 0.01 & $4.32(0.87-21.59)$ & 0.07 \\
\hline \multirow[t]{2}{*}{ Physical Activity } & Active & reference & & & \\
\hline & Inactive & $3.29(1.36-7.98)$ & 0.009 & $4.05(1.44-11.38)$ & 0.008 \\
\hline \multirow[t]{2}{*}{ Meditation } & Yes & reference & & & \\
\hline & No & $0.49(0.30-0.79)$ & 0.003 & $0.80(0.43-1.47)$ & 0.47 \\
\hline
\end{tabular}

obese which is $35.8 \%$. The prevalence of hypertension was $32.6 \%$ (100/307) among study subjects. The hypertension was significantly higher in individuals of age group 25-77 years than those less in the 18-24 age group.

Bivariate and multivariate logistic regression was used to determine independent association of the risks factors. Crude and adjusted odds ratio were obtained for all variables with different significance level. Age group of 36-77 years has higher odds than 18-24 years age group (Figure 1). They are 15.8 times at risk of hypertension with a $\mathrm{p}$-value $<0.01$. Alcohol consumption, betel use, low physical activity were also found significant predictors of hypertension with a p-value $<0.05$ (Table 1).

Out of 100 subjects who are hypertensive, only $26 \%$ of the subjects are receiving hypertension medications and remaining $74 \%$ of the subjects do not seek any treatment (Figure 2).

\section{DISCUSSION}

The prevalence of hypertension in the study population was significantly higher in comparison with the prevalence reported in a similar study in Bhutan. The difference in rate observed between the present study and other studies could be due to differences in lifestyle and dietary habits, a segment of the population, and the research methodology used. The present study showed that the prevalence of hypertension was significantly higher in individuals from age 25 years and above as compared to those who are from 18-24 years. Kishore et al (2016) assert Hypertension increase with the increase of age is a well-known fact now [6]. Thus, the study showed age as one of the main risk factors and is strongly associated with hypertension. A similar study was conducted by Tshering et al (2011) among 138 monks in Bhutan and it was found that age was closely associated with the development of hypertension [7]. No significant association was found between hypertension and their duration as monks but significant differences were found in alcohol consumption among the subjects. This is consisted with the findings in studies conducted by Tshering, Todkar et al in India, Wei et al in China, and Dhungana et al. which revealed that alcohol users are at more risk of developing hypertension as compared to non-drinkers and have high association with hypertension as it increases blood pressure as calories from alcohol are contributed to weight gain [8-11,13]. 
In the study, the majority of the subjects were found to consume betel nut in huge quantity and its association with hypertension was significant. This is supported from the findings by Lin et al (2008) that chewing betel nut is highly associated with a greater risk of cardiovascular diseases [12]. The prevalence of hypertension was found to be constantly increased with high BMI among obese and overweight individuals as than with the subjects who have normal BMI and underweight individuals [8]. This was presented in a study conducted by Dhungana et al in India. Physical activity was found to be another modifiable risk factor for hypertension in the study. Subjects who are not involved in any kind of physical exercises, they are 4.05 times more likely to develop hypertension. This is supported with the findings from Tabrizi et al (2016) and Peymani et al (2012) studies where a low level of physical activity was found as an independent risk factor for hypertension $[13,14]$.

\section{CONCLUSION AND RECOMMENDATION}

Hypertension is significantly higher in older age group which concludes that hypertension increase with the increase of age. Alcohol use, betel consumption, and physical inactivity were found to be significant risk factors for developing hypertension. With the $32.6 \%$ prevalence rate, only $26 \%$ of them are receiving medications. There is an impending need for effective intervention strategies. In addition, further research and awareness campaigns are essential among monks population in Bhutan.

\section{ACKNOWLEDGMENTS}

I extend profound gratitude to the Science and Math Program, Department of Public Health, AUW for funding this research. I am also deeply grateful for AUW IRB for approving this research and lastly, the Monastic Body of Bhutan, Zam for equipment, my parents, sisters, and friends for supporting me throughout the study.

\section{REFERENCES}

1. Singh, S., Shankar, R., \& Singh, G. P., 2017. Prevalence and Associated Risk Factors of Hypertension: A Cross-Sectional Study in Urban Varanasi. International journal of hypertension, 2017, 5491838.

2. Hien, H., Tam, N., Tam, Vo., Derese, A., and Devroey, D., 2018. "Prevalence, Awareness, Treatment, and Control of Hypertension and Its Risk Factors in (Central) Vietnam," International Journal of Hypertension, vol. 2018, Article ID 6326984, 12 page.

3. World Health Organization., 2014. WHO region - South East Asia 2014.

4. Ministry Of Health., 2009. Report on 2007 STEP Survey for Risk Factors and Prevalence of Non-Communicable Diseases in Thimphu. Royal Government of Bhutan.

5. Annual Heath Bulletin 2017. Royal Government of Bhutan. pp 1-132.

6. Kishore, J., Gupta, N., Kohli, C. and Kumar, N., 2016. Prevalence of hypertension and determination of its risk factors in rural Delhi. International journal of hypertension, 2016

7. Todkar, S.S., Gujarathi, V.V. and Tapare, V.S., 2009. Period prevalence and sociodemographic factors of hypertension in rural Maharashtra: a cross-sectional study. Indian journal of community medicine: official publication of Indian Association of Preventive \& Social Medicine, 34(3), p.183

8. Dhungana, R.R., Pandey, A.R., Bista, B., Joshi, S. and Devkota, S., 2016 Prevalence and associated factors of hypertension: a communitybased cross-sectional study in municipalities of Kathmandu, Nepal. International journal of hypertension, 2016.

9. Tshering, Namgay., Somrongthong, Ratana., 2011.The Prevalence and Determinants of Hypertension among Bhutanese monks in Thimphu Tashichoedzong. Policy and Planning Division, Ministry of Health, Thimphu, Bhutan.

10. Wei, Q., Sun, J., Huang, J., Zhou, H.Y., Ding, Y.M., Tao, Y.C et al., 2015. Prevalence of hypertension and associated risk factors in Dehui City of Jilin Province in China. Journal of human hypertension, 29(1), p.64.

11. Ministry Of Health., 2009. Report on 2007 STEP Survey for Risk Factors and Prevalence of Non-Communicable Diseases in Thimphu. Royal Government of Bhutan

12. Lin, W.Y., Chiu, T.Y., Lee, L.T., Lin, C.C., Huang, C.Y. and Huang, K.C. 2008. Betel nut chewing is associated with increased risk of cardiovascular disease and all-cause mortality in Taiwanese men. The American journal of clinical nutrition, 87(5), pp.1204-1211.

13. Tabrizi, J.S., Sadeghi-Bazargani, H., Farahbakhsh, M., Nikniaz, L. and Nikniaz, Z., 2016. Prevalence and associated factors of prehypertension and hypertension in Iranian population: the Lifestyle Promotion Project (LPP). PloS one, 11(10), p.e0165264.

14. Peymani, P., Heydari, S.T., Ahmadi, S.M., Sarikhani, Y., Joulaei, H., Moghadami, M. et al., 2012. The Prevalence of High Blood Pressure and Its Relationship with Anthropometric Indicators; a Population Based Study in Fars Province, IR Iran. International Cardiovascular Research Journal, 6(2).

Note:

Kindly note after updating the corrections the Reference number 4 and 11 (Highlighted) seems to be same. So, please check and advice. 